\title{
Juvenile Recurrent Parotitis
}

\author{
Parminder Singh ${ }^{1} \cdot$ Divya Gupta ${ }^{2}$
}

Received: 10 June 2018 / Accepted: 8 February 2019 / Published online: 20 February 2019

(C) Dr. K C Chaudhuri Foundation 2019

To the Editor: Juvenile recurrent parotitis (JRP) is a rare, recurrent non-obstructive, and non-suppurative parotid inflammation having a multifactorial etiology. Many causative factors such as allergy, infection, local autoimmune manifestations and genetic inheritance have been suggested, but none have been proved [1, 2]. MR sailography has become the modality of investigation in recent times [1-3]. Treatment is mostly conservative with analgesics, attention to good oral hygiene, massage of the parotid gland, warmth, use of chewing gum and sialogogic agents. However aggressive interventions in the form of sialendoscopy and surgical management are resorted to in cases of persistent and recurrent symptoms [3, 4].

We report 3 such cases of JRP that presented to our centre with recurrent parotid swelling. The patient profiles are cited in Table 1. None of them had any other significant past or family history or any history suggestive of autoimmune disorders. All of them had been immunized as per age as per universal immunization program. On examination parotid swellings were smooth, soft to firm in consistency, tender with pressure over the gland not resulting in any purulent discharge from the parotid duct. Oral hygiene was adequate in all children. Their blood counts, erythrocyte sedimentation rate and serum immunoglobulin levels were normal. Human immunodeficiency virus (HIV) serology, rheumatoid factor, antibodies including anti-Ro and anti-La for Sjogren's syndrome were negative. Ultrasound of swelling was suggestive of chronic inflammation with fine needle aspiration cytology (FNAC) favoring the diagnosis of sialoadenosis. All children were given symptomatic treatment as mentioned earlier and in case of severe symptoms short course of broad spectrum antibiotics

Divya Gupta

divzafmc@gmail.com

1 Department of Pediatrics, 155 Base Hospital, Tezpur, Assam 784001, India

2 Department of Pathology, 155 Base Hospital, Tezpur, Assam 784001, India
Table 1 Patient profile

\begin{tabular}{llllllll}
\hline $\begin{array}{l}\text { S. } \\
\text { No }\end{array}$ & Age & Sex & Onset & $\begin{array}{l}\text { No. of } \\
\text { episodes }\end{array}$ & $\begin{array}{l}\text { Unilateral/ } \\
\text { bilateral }\end{array}$ & USG & Management \\
\hline 1 & 3 y & F & 2 y & 10 & Bilateral & Parotitis & Conservative \\
2 & 4 y & F & 2 y & 07 & Bilateral & Parotitis & Conservative \\
3 & 3 y & M & 1.5 y & 04 & Bilateral & Parotitis & Conservative \\
\hline
\end{tabular}

were given for 5 to $7 \mathrm{~d}$. The first child continues to be symptomatic once in 2 to 3 mo while the rest two cases have been asymptomatic and are on regular follow up for the past $1 \mathrm{y}$.

To conclude recurrent parotid swelling can not only be a diagnostic dilemma but may also be a significant cause of morbidity in school going children. At times conservative approach may fail to bring symptomatic relief requiring more invasive modalities of treatment.

\section{Compliance with Ethical Standards}

Conflict of Interest None.

Source of Funding None.

Publisher's Note Nature remains neutral with regard to jurisdictional claims in published maps and institutional affiliations.

\section{References}

1. Tomar RPS, Vasudevan R, Kumar M, Gupta DK. Juvenile recurrent parotitis. Med J Armed Forces India. 2014;70:83-4.

2. Bhat VS, Yanamadala S. Juvenile recurrent parotitis: a case report. Sch J App Med Sci. 2015;3:3086-8.

3. Rao VVN, Buddi JSHP, Kurthukoti AJ. Juvenile recurrent parotitis in children: diagnosis and treatment using sialography. J Indian Soc Pedod Prev Dent. 2014;32:262-5.

4. Quenin S, Plouin-Gaudon I, Marchal F, Froehlich P, Disant F, Faure F. Juvenile recurrent parotitis sialendoscopic approach. Arch Otolaryngol Head Neck Surg. 2008;134:715-9. 